\section{Degradation of Persistent RNA in RNase-Contain- ing, High-Throughput Alkaline Lysis DNA Preparations}

BioTechniques 29:250-252 (August 2000)

Non-matrix-binding high-throughput alkaline lysis DNA preparations are being used worldwide to isolate sequencing substrates for genome sequencing projects. With the increased use of capillary sequencers, such as the ABI PRISM ${ }^{\mathrm{TM}}$ model 3700 from PE Biosystems (Foster City, CA, USA) and MegaBACE ${ }^{\mathrm{TM}}$ from Molecular Dynamics (Sunnyvale, CA, USA), the requirement for clean plasmid DNA has also increased. Most of these methods attempt to remove RNA by the addition of RNase A or a combination of RNase $\mathrm{A} / \mathrm{T} 1$ to the cell resuspension buffer. Visualization of the completed DNA preparation on an ethidium bromidestained agarose gel, however, often reveals incomplete RNA removal, especially when clones are grown in rich media such as $2 \mathrm{xYT}$ or TB.

The procedure described here uses the residual RNase in the finished preparation to remove persistent RNA by incubating the resuspended DNA at $62^{\circ} \mathrm{C}$ for $5-10 \mathrm{~min}$. Sufficient RNase, originally added to the cell resuspension buffer, remains throughout the alkaline lysis preparation and DNA precipitation to be effective during the heating step. Additional RNase is not needed. Both RNase A and RNase T1 were found to have dramatic improvements in degradation of residual RNA during the $62^{\circ} \mathrm{C}$ heating step, and the two used together were most effective. Our experiments show that oligo-RNAs not degraded by regular protocols are resistant to RNase at normal enzymatic temperatures (Figure 1). This contradicts the typical attribution of incomplete RNA removal-that alkaline lysis preparations do not usually require a $37^{\circ} \mathrm{C}$ incubation step (normal enzymatic activity temperature) before the RNase is subjected to the denaturing conditions of alkaline lysis.

What we may have observed is the

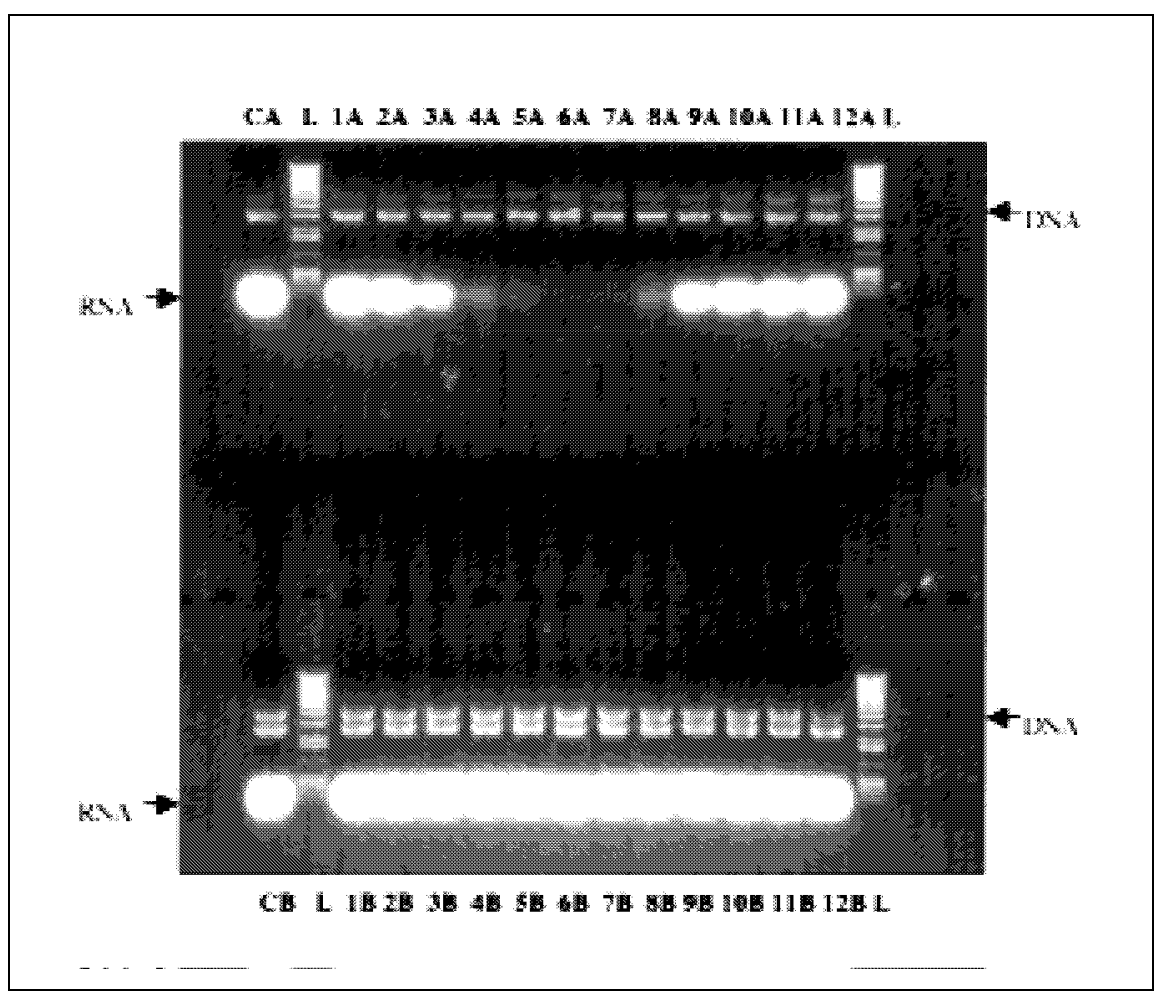

Figure 1. Degradation of residual RNA by RNase A/T1 in a range of temperatures. DNA preparations were conducted using R.E.A.L. ${ }^{\text {TM }} 96$ Prep (Qiagen, Valencia, CA, USA). The manufacturer's guidelines were followed unless otherwise noted. Lanes $1 \mathrm{~A}-12 \mathrm{~A}$ and $1 \mathrm{~B}-12 \mathrm{~B}$ are aliquots of the same preparation. RNase $\mathrm{A} / \mathrm{T} 1$ were added to lanes $1 \mathrm{~A}-12 \mathrm{~A}$, and the samples were incubated at their respective temperature for $5 \mathrm{~min}$. Here, RNase was added to the DNA resuspension buffer after alkaline lysis; however, similar results were obtained when the RNase was added to the cell resuspension buffer only. After incubation, samples were kept on ice until a portion was loaded on agarose gel. Lanes 1B-12B did not have RNase $\mathrm{A} / \mathrm{T} 1$ added and were incubated at their respective temperatures for $5 \mathrm{~min}$. Lanes were incubated as follows: $1 \mathrm{~A} / \mathrm{B}, 37^{\circ} \mathrm{C} ; 2 \mathrm{~A} / \mathrm{B}, 40^{\circ} \mathrm{C} ; 3 \mathrm{~A} / \mathrm{B}, 45^{\circ} \mathrm{C} ; 4 \mathrm{~A} / \mathrm{B}, 50^{\circ} \mathrm{C} ; 5 \mathrm{~A} / \mathrm{B}, 55^{\circ} \mathrm{C} ; 6 \mathrm{~A} / \mathrm{B}, 60^{\circ} \mathrm{C} ; 7 \mathrm{~A} / \mathrm{B}$, $65^{\circ} \mathrm{C} ; 8 \mathrm{~A} / \mathrm{B}, 70^{\circ} \mathrm{C} ; 9 \mathrm{~A} / \mathrm{B}, 75^{\circ} \mathrm{C} ; 10 \mathrm{~A} / \mathrm{B}, 80^{\circ} \mathrm{C} ; 11 \mathrm{~A} / \mathrm{B}, 85^{\circ} \mathrm{C} ; 12 \mathrm{~A} / \mathrm{B}, 90^{\circ} \mathrm{C}$. Lane L contains a $1-\mathrm{kb}$ size ladder. Lane $\mathrm{CA}$ is an aliquot of the preparation that had RNase A/T1 added and was kept on ice through the incubation. Lane CB is an aliquot of the preparation that did not have RNase A/T1 added and was kept on ice through the incubation. Note that at $37^{\circ} \mathrm{C}$, RNA is not removed, even in the presence of RNase. Complete RNA removal is obtained with the combination of RNase $\mathrm{A} / \mathrm{T} 1$ between $60^{\circ} \mathrm{C}$ and $65^{\circ} \mathrm{C}$.

temperature at which the most RNA becomes susceptible, yet at which enough RNase maintains activity to degrade the RNA (Figure 1). RNase T1 is known to denature at around $59^{\circ} \mathrm{C}(1)$, while RNase $\mathrm{A}$ is known to denature at around $65^{\circ} \mathrm{C}$ (2) with the denaturing temperature increasing at a higher $\mathrm{pH}$ (2). The $\mathrm{pH}$ of TE-resuspended DNA preparations is normally between $\mathrm{pH}$ 7.5 and $\mathrm{pH}$ 8.0. The method has been applied to preparation kits from different manufacturers and has proven effective in all cases.

\section{REFERENCES}

1.Pace, C.N., G.R. Grimsley, J.A. Thomson and B.J. Barnett. 1988. Conformational sta- bility and activity of ribonuclease $\mathrm{T} 1$ with zero, one, and two intact disulfide bonds. J. Biol. Chem. 263:11820-11825.

2.Tsai, A.M., J.H. van Zanten and M.J. Betenbaugh. 1998. I. Study of protein aggregation due to heat denaturation: a structural approach using circular dichroism spectroscopy, nuclear magnetic resonance, and static light scattering. Biotechnol. Bioeng. 59:273-280.

The authors would like to thank the BAC Ends Team at TIGR for putting our results through high-throughput testing over a long period of time. We would also like to thank Tamara Feldblyum for her support of this study. We thank those who participated in the review of this manuscript. Address correspondence to Joel A. Malek, The Institute for Genomic Research, 9712 Medical Center Drive, Rockville, MD 20850, USA. e-mail:jamalek@tigr.org 
Received 24 January 2000; accepted 10 April 2000.

Joel A. Malek, Sofiya Y. Shatsman, Bola A. Akinretoye and John E. Gill The Institute for Genomic Research Rockville, MD, USA

\section{Irreversible Heat Inacti- vation of DNase I without RNA Degradation}

BioTechniques 29: 252-256 (August 2000)

In many applications of RT-PCR, residual genomic DNA in total RNA preparations is amplified together with
RNA, which results in false-positive data. One way to overcome this problem is to design primers that span a region containing one or more introns, thereby creating a diagnostic size difference between the amplification products originating from the RNA or the DNA. However, this method will not work in many organisms containing genes without introns (6). Additionally, in quantitative or semi-quantitative RT-PCR, the contaminating DNA will compete with cDNA for primers, which can lead to misinterpretation of the results. Preexisting DNA can also result in the appearance of additional differential bands during differential display (8) or cDNA-AFLP (1). In known sequences, DNA contamination can be eliminated by restriction endonuclease digestion before the amplification of cDNA (5). In short target regions, however, the choice of restriction enzymes is very limited, and because sequence knowledge is required, this method is not generally applicable. Moreover, these restriction fragments may still act as amplification primers and produce a nonspecific smear.

The most effective and universal way to eliminate genomic DNA is enzymatic treatment with DNase I. In the presence of magnesium ions, DNase I cleaves each DNA strand independently, while in the presence of manganese ions, both strands are cleaved at approximately the same site (10). Manganese ions can be used at a concentration ten times lower $(0.66 \mathrm{mM})$ than magnesium ions, and they can prevent the production of artifacts in RT-PCR arising from the recombination of overlapping fragments that are created by DNase I treatment using magnesium as a cofactor (2). In addition, at commonly used concentrations, magnesium ions can significantly influence the thermostability of DNase I and contribute to the reactivation of the enzyme after heat treatment (3).

For reverse transcription of RNA, irreversible inactivation of DNase I can be achieved in two ways. First, the RNA can be extracted with phenol/ chloroform, but this method is time consuming, results in RNA loss and can be problematic at low RNA concentrations. A second method consists of heat denaturation of DNase I at $75^{\circ} \mathrm{C}$ for 5 min. Using this method, no significant 